\title{
Designing iDTV Applications from Participatory Use of Patterns
}

\author{
Samuel B. Buchdid, Roberto Pereira, and M. Cecília C. Baranauskas \\ Institute of Computing, State University of Campinas, Av. Albert Einstein N1251, \\ Campinas-SP, Brazil \\ \{buchdid, rpereira, cecilia\}@.ic.unicamp.br
}

\begin{abstract}
Interactive Digital TV (iDTV) is an emerging technology in Brazil, with inherent characteristics that must be addressed and which demand technical resources and references to support the design and development of interactive applications. This paper presents a design activity that reports and discusses the use of specific design patterns combined with prototyping tools and techniques inspired by Participatory Design in the design of applications for iDTV. Results are presented and discussed focusing on: the advantages of using design patterns in a participatory design, the main difficulties the groups had during the design activities, the importance of tools to support the design of iDTV applications.
\end{abstract}

Keywords: Interactive Digital TV, Design Patterns, Participatory Design, HCI.

\section{Introduction}

In 2003, the Brazilian government created the Brazilian Digital Television System with the aim of promoting democratization of information [5]. The analogical television is present in over $97 \%$ of Brazilian homes [10] and can be considered the main source of communication and entertainment in Brazil. Considering the major indexes regarding social and economic inequalities in the country, iDTV presents itself as a promising vehicle for the dissemination of information and education [20], and it may contribute to social and digital inclusion by reducing barriers that prevent the participatory and universal access of Brazilian citizens to knowledge: one of the 5 Grand Challenges of research in Computing in the country [2].

iDTV presents some challenges inherent to its technology that must be considered in the design of an interactive application. For instance: i) interaction (limited) by a remote control; ii) limited processing and memory capacity; iii) the physical distance between the user and the television; iv) the limitations in terms of input and output devices (keyboard and mouse); v) the diversity (cognitive, physical, socioeconomic, cultural) of users; vi) the usual presence of other viewers in the same place; and vii) the population's lack of experience in interacting with television content $[6,11,18]$. In fact, only recently standards were approved and receptors became able to receive the iDTV applications [4]. Hence, in Brazil there are still few applications available, and few users have access to interactive contents. 
Considering the lack of technical artifacts and tools specific to the iDTV context, this paper presents and discusses the experience of using Design Patterns articulated with techniques inspired by Participatory Design [14] and prototyping tools (e.g., Balsamiq $^{\circledR}$ and CogTool $^{\circledR}$ ) for supporting the design of iDTV applications. The discussion of the paper is situated within a practical context of design in which eight different applications were designed by prospective designers to support social interaction through iDTV. The focus of this contribution is on the effectiveness of design patterns and its use in participatory practices to face the lack of support and technical resources, and to establish a first contact with the new technology. As a contribution, we are going to present and discuss: the patterns that were (and were not) used from the selected pattern collection; the main difficulties participant groups had during the design activities; the importance of technical resources to support the design; the benefits of articulating the usage of design patterns with techniques from the participatory design; important aspects that must be taken into account when designing iDTV applications for a wide audience (e.g., privacy, autonomy, accessibility); and suggestions for an authoring tool to support inexperienced designers in the iDTV context.

The paper is organized as follows: section 2 presents the main concepts related to design patterns and their relationships with emerging technologies; it also presents the collection of patterns for iDTV used in this study. Section 3 describes the case study in which the patterns for iDTV were used; it also presents and discusses the results of the case study based on an assessment by the participants. Finally, section 4 presents the final considerations about the work and directions for future research.

\section{Design Patterns}

Design patterns were originally proposed by the architect and urban planner Christopher Alexander in the 1970s. The main concept brings the idea of capturing the essence of successful solutions to recurring problems of architectural projects in a given context [1].

In addition to their use in the field of architecture, design patterns has been used in fields, such as Software Engineering [8] and Human-Computer Interaction (HCI) [3] and other contexts, such as Ubiquitous Computing [7], Web [13] and iDTV [11].

Compared to other forms of design guidance for interactive applications, such as guidelines, design principles and style guides, design patterns are slightly more extensive and therefore require more time to be understood and used. However, as Kunert [11] and Chung et. al. [7] discuss, design patterns have advantages: i) they are distributed in a hierarchical structure, which makes it easier to locate and differentiate between patterns of different granularity, which are situated at different levels of structure; ii) they are proposed in a language that is simple to those who use them; and iii) they incorporate references that may indicate other forms of design guidance, etc. 


\subsection{Patterns for iDTV}

Studies that involve design patterns and report on experiences of success that could inspire other social contexts, such as that of Brazil, are still scarce. Some authors have previously identified a list of usability patterns for specific iDTV interactive tasks [19]. The pattern collection used in this work was proposed by Kunert [11] with a focus on interaction design for iDTV applications and special attention to usability issues. The patterns are divided into 10 groups. See Table 1.

Table 1. Groups of Patterns. Adapted from Kunert [11]

\begin{tabular}{|c|c|}
\hline Name & Description \\
\hline $\begin{array}{l}\text { Group A: } \\
\text { Page Layout }\end{array}$ & $\begin{array}{l}\text { This group of patterns defines the layout types to be used in the application (e.g., } \\
\text { overlay, full-screen with video, full-screen without video) and when to use each of } \\
\text { them. It also determines the distribution of navigation elements, video and content. }\end{array}$ \\
\hline $\begin{array}{l}\text { Group B: Naviga- } \\
\text { tion }\end{array}$ & $\begin{array}{l}\text { Defines what types of navigation are to be used in the application, ideally, after } \\
\text { choosing the layout (Group A). For example: menus, index tabs. }\end{array}$ \\
\hline $\begin{array}{l}\text { Group C: Remote } \\
\text { Control Keys }\end{array}$ & $\begin{array}{l}\text { Defines the main keys of the remote control (e.g., colorful, numerical, arrow) and } \\
\text { how they should be used in the whole application. For example: the color keys are } \\
\text { usually used when only a key press is needed. Use color keys for choices that have } \\
\text { to be efficient and for choosing an item in a menu. }\end{array}$ \\
\hline \multirow{2}{*}{$\begin{array}{l}\text { Group D: Basic } \\
\text { Functions } \\
\text { Group E: Content } \\
\text { Presentation } \\
\end{array}$} & $\begin{array}{l}\text { Highlights the basic functions that should be considered in the design of interaction } \\
\text { and describes how to start, load, exit and hide an application, among other tasks. }\end{array}$ \\
\hline & $\begin{array}{l}\text { Determines the basic elements that form an application, such as text design (e.g., } \\
\text { size, color and type), paging, content box, content update indication, etc. }\end{array}$ \\
\hline $\begin{array}{l}\text { Group F: User } \\
\text { Participation }\end{array}$ & $\begin{array}{l}\text { Describes how the interaction project on specific tasks should occur, i.e., the } \\
\text { multiple types of user participation, such as voting and multiple-choice questions. It } \\
\text { also describes how to conduct the approval for connectivity when the application } \\
\text { needs to use the return channel and when the user's consent is required. }\end{array}$ \\
\hline $\begin{array}{l}\text { Group G: Text } \\
\text { Input }\end{array}$ & $\begin{array}{l}\text { Defines the multiple ways to input text (e.g., on-screen qwerty or alphabetical } \\
\text { keyboard, mobile phone keyboard), when to use each, and how to use them in an } \\
\text { application }\end{array}$ \\
\hline Group H: Help & $\begin{array}{l}\text { Defines the types of help (e.g., help section, on-screen instruction) and how provide } \\
\text { them in an appropriate way to users according to the context of use. }\end{array}$ \\
\hline $\begin{array}{l}\text { Group I: Accessi- } \\
\text { bility \& Personali- } \\
\text { zation }\end{array}$ & $\begin{array}{l}\text { Deals with accessibility and personalization issues. For example: font size, subtitles, } \\
\text { sign-language interpreter, audio feedback, option settings, etc. }\end{array}$ \\
\hline $\begin{array}{l}\text { Group J: Specific } \\
\text { User Groups }\end{array}$ & $\begin{array}{l}\text { Illustrates patterns for specific user groups (e.g., children). For example, how to } \\
\text { define the menu, the remote control keys, etc. }\end{array}$ \\
\hline
\end{tabular}

Each of the 10 groups describes and illustrates first-level problems that are divided into new design problems of second and third levels. On the second level, there are 35 interaction problems; for each one, there is a corresponding pattern. For example, to define the application layout (first level: "Group A: Page Layout"), designers should choose from 3 different types of layout according to the constraints of the application being designed: "A2 Overlay", "A3 Full-Screen with Video" and "A4 Full-Screen without Video". On the third level, there are more specific problems that guide the solutions of the first and second levels. Regarding "Group A", these types of problems are characterized by the position and size of the application that is layered over the video, the position and size of the video, transparency issues, the application audio competing with the audio of the video, etc. 
A pattern must follow a structure that is inherent to the purpose of the language or to the set of patterns on which it is inserted [3]. Kunert's iDTV patterns [11] are characterized by: 1. Reference: a unique identifier in the pattern collection ("A4"). 2. Name: usually describes the effect of using the pattern ("Full-Screen without Video"). 3. Examples: ways to use pattern (e.g., images that illustrate the pattern being used in practice). 4. Context: introductory paragraph contextualizing the use of the patterns. 5. Problem: shows the forces involved in the use of the pattern, aspects to be considered, etc. 6. Solution: different and generic ways of solving the problem. 7. Evidence: references and usability tests used to demonstrate the viability of the proposed solutions. 8. Related Patterns: patterns that influence and/or are influenced by the pattern in question.

In the next section, we present a case study in which the patterns presented were used to support the design of iDTV applications.

\section{Case Study}

The case study was conducted from August to December, 2011, and involved 38 prospective designers that were attending a Computer Science discipline for the "Design of Human-Computer Interfaces". The participants were divided into 8 groups: G1 (formed by the prospective designers: D1, D2, D3 and D4), G2 (D5-D9), G3 (D10-D14), G4 (D15-D19), G5 (D20-D23), G6 (D24-D28), G7 (D29-D33) and G8 (D34-D38). From the 38 participants, only D15 had already had some contact with the design of iDTV applications, but had no experience with Design Patterns. The other participants were aware of the existence of iDTV applications, but had never designed or even experienced them as end users.

The project developed by the groups was related to the design of "sustainable and social applications for iDTV". From the 8 groups, G2 designed a game to teach the concept of sustainability to children. G3 presented the prototype of an application for promoting social interaction during soccer matches on TV. G4 and G5 designed applications related to social networks for iDTV. G6 designed a social application to promote sustainable behavior in users. G7 designed an application to support an online chat, and G8 designed an application that complements educational courses via iDTV. At the end of the course, groups had to present an interactive prototype of their applications and share the results with each other.

After the course was finished, groups were asked to voluntarily answer an online questionnaire in order to evaluate the activities. At this time, groups were asked for their permission to use all the material they produced during the course and their answers to the questionnaire. G1 opted not to answer the evaluation questionnaire and is not included in the analysis presented in this paper.

Before using the iDTV patterns, groups conducted activities that favored problem clarification, analysis, and requirement refinement and organization. Artifacts from and based on the Organizational Semiotics [12] were used to support the identification of the stakeholders involved in the project, their cultural aspects, values, problems and ideas, and requirements to be considered in the design. In such applications, the concern with the culture and values of the different stakeholders were mandatory. The problem clarification and evaluation based on culture and values can be found in detail in [16] and [17], respectively. 
Before starting the design activities, the pattern collection and examples were presented and discussed with the groups in a lecture. As support material, each group received a summary of the 10 groups of patterns presenting the name and a general description for each group, as well as all the patterns placed in each group, including their names, references, problems (description, advantages and disadvantages) and solutions. Generic patterns were incorporated into specialized patterns in order to simplify the activity and reduce the number of patterns to be analyzed.

The activity with Design Patterns for iDTV was organized into 3 steps:

1. In the first step, participants selected the patterns that would be used in their applications. With the list of patterns provided to support the activity, participants needed to justify their choices based on the scope of their applications and the inherent forces of each pattern.

2. For the creation of the first interface prototypes, participants were involved in participatory design activities (Brain Drawing [14] adapted) guided by the design patterns for iDTV. Participants received paper, pencils and pens to draw their ideas, respecting the design constraints and the previously selected patterns. As a result, each group created several interface proposals constructed by each participant and consolidated into a final proposal.

3. The material produced in the step 2 was used as a basis for designing the interface and for producing the first interactive version of the system prototype. Fig. 1 shows some examples of prototypes designed by G2, G3 and G8. The Balsamiq ${ }^{\circledR}$ tool was suggested to design interfaces and the $\operatorname{CogTool}^{\circledR}$ was used to model the tasks and create the interactive prototypes.

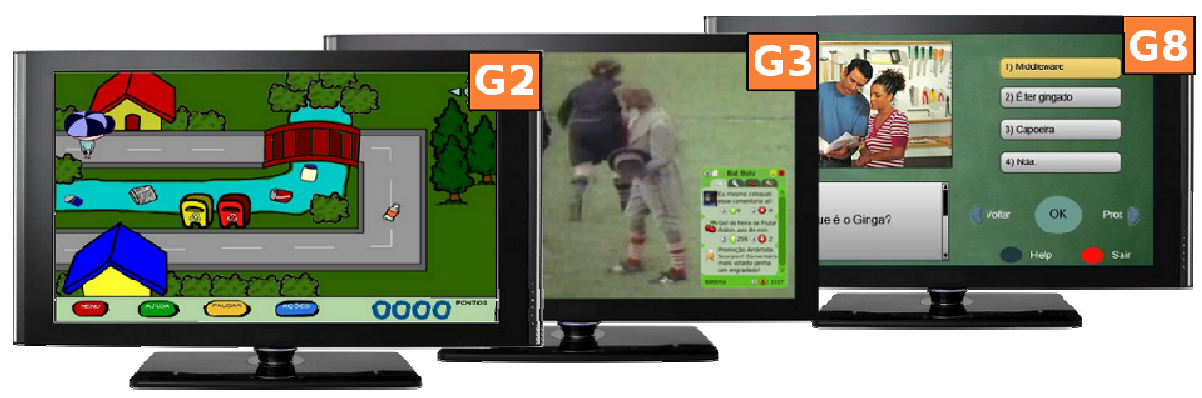

Fig. 1. Prototypes of Groups G2, G3 and G8

Other tools specific to the iDTV context were analyzed during the project - for instance: JAME Author ${ }^{\circledR}$, iTVProject ${ }^{\circledR}$, Composer $^{\circledR}$, Batuque ${ }^{\circledR}$ and BluTV ${ }^{\circledR}$. However, none of them was viable for the project due to the need to acquire licenses, and sometimes due to the project's discontinuity or to the impossibility of obtaining the tool at the time of the case study. Participants were also encouraged to use emulators (GingaNCL [9] and Open Ginga [15]) with the NCL Eclipse ${ }^{\circledR}$ plug-in, but none of the groups chose this option due to the lack of time and the difficulty of learning a new programming language while developing the project. 


\subsection{Results and Discussion}

All the initial layouts produced by the groups contained the design patterns that were kept in the final prototype. Fig. 2 illustrates the prototype created by G3 at three different design moments: $1^{\text {st }}$ : after participatory design; $2^{\text {nd }}$ : in an intermediate step; and $3^{\text {rd }}$ : after the project was finished.

In Fig. 2, it is possible to see that higher level patterns, such as "A3 Full-Screen with Video", "B2 Menu" and "B6 Tabs" remained present at the different prototypes' stages. More specific patterns, such as "C2 Arrow Keys", "C3 OK-Key", "D4 Exiting", "H1 On-Screen Instruction" and "H2 Help Section" were incorporated into the prototypes as the design evolved.

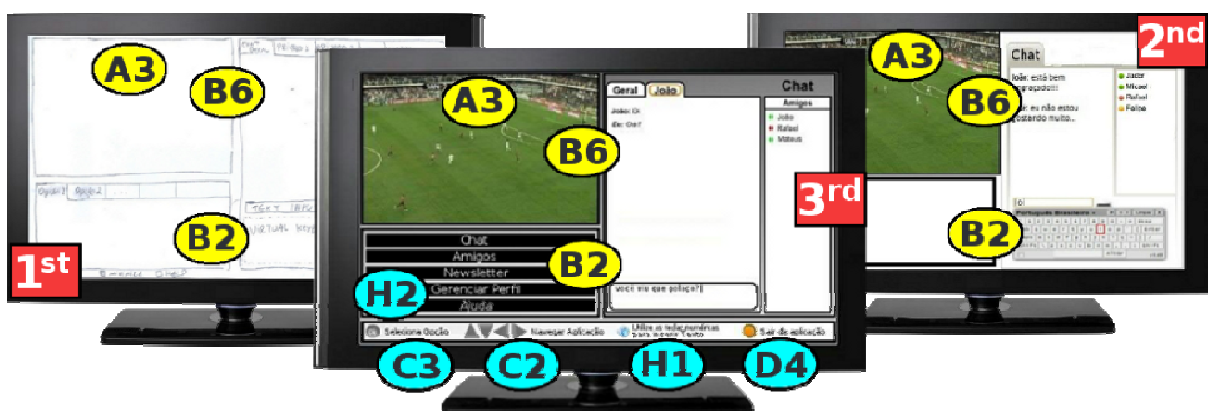

Fig. 2. Evolution of G3's Prototype since Brain Drawing Activity with Indicated Patterns

Considering the final prototype from each group, it was possible to make a mapping of all the patterns used in the activity (see Table 2). Each row of Table 2 corresponds to a pattern present in the summary given to the participants and each column represents the groups and their projects. Cells are labeled according to the following legend:

- " $\checkmark "$ - indicates that the pattern was identified in the final prototype of the corresponding group and was used in accordance with its proposal.

- " $\boldsymbol{X}$ " - indicates that the pattern was not in accordance with its proposal (e.g., G3 used the pattern "A2 Overlay" in an application that requires high cognitive effort and did not provide a reason for the choice).

- "C" - indicates that there is a conflict among the patterns used (e.g., G5 used all the existing layouts). Preferably, the application should use the same layout across its different interfaces in order to keep the application's identity.

- "?" - Indicates that the pattern should have been used according to the television context (e.g., "D1 Initial Call to Action" or "D4 Exiting"), or according to the design requirements identified (e.g., "I1 Accessibility"), but, for different reasons, they were not used.

- The cells that do not have marks indicate that the patterns were not identified in the project, and have no direct implications in the final prototype. 
Table 2. List of Patterns Used in Final Prototypes

\begin{tabular}{|c|c|c|c|c|c|c|c|}
\hline Padrão & G2 & G3 & G4 & G5 & G6 & G7 & G8 \\
\hline A2 OVERLAY & & $x$ & & $\mathbf{C}$ & & & \\
\hline $\begin{array}{l}\text { A3 FULL-SCREEN } \\
\text { WITH VIIDEO }\end{array}$ & & & & C & $\checkmark$ & C & C \\
\hline $\begin{array}{l}\text { A } 4 \text { FULL-SCRENEN } \\
\text { WITHOUT VIIDEO }\end{array}$ & $v$ & & $v$ & C & & C & C \\
\hline B2 MENU & $\checkmark$ & $\checkmark$ & $\checkmark$ & $\checkmark$ & $\checkmark$ & $\checkmark$ & $\checkmark$ \\
\hline B4 INDEX & & & & & & $v$ & $\checkmark$ \\
\hline B5 PAGE NUMBERS & & & 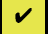 & & & & \\
\hline B6 TABS & & $v$ & & $\checkmark$ & & $v$ & \\
\hline C2 ARROW KEYS & $\checkmark$ & $\checkmark$ & $\checkmark$ & $\checkmark$ & $\checkmark$ & $\checkmark$ & $\checkmark$ \\
\hline C3 OK-KEY & $\checkmark$ & $v$ & $v$ & $\checkmark$ & $\checkmark$ & $v$ & $v$ \\
\hline C4 COLOUR KEYS & $\checkmark$ & $\checkmark$ & & $\checkmark$ & & $v$ & $\checkmark$ \\
\hline C5 NUMBER KEYS & & $\checkmark$ & & & & $\checkmark$ & $\checkmark$ \\
\hline \multicolumn{8}{|l|}{ C6 SPECIAL KEYS } \\
\hline $\begin{array}{l}\text { D1 INITIAL CALL } \\
\text { TO ACTION }\end{array}$ & $?$ & $?$ & $?$ & $?$ & $?$ & $v$ & $?$ \\
\hline D2 STARTING & $?$ & $v$ & $?$ & $?$ & $?$ & $v$ & $?$ \\
\hline $\begin{array}{l}\text { D3 LOADING } \\
\text { INDICA TION } \\
\end{array}$ & $?$ & $?$ & $?$ & $?$ & $?$ & $v$ & $?$ \\
\hline D4 EXITING & $?$ & $\checkmark$ & $\checkmark$ & $\checkmark$ & $?$ & $\checkmark$ & $\checkmark$ \\
\hline $\begin{array}{l}\text { D5 HIDING } \\
\text { APPLICATION } \\
\end{array}$ & $?$ & $v$ & $?$ & $\checkmark$ & $?$ & $v$ & $?$ \\
\hline $\begin{array}{l}\text { D6 GOING ONE } \\
\text { LEVEL UP }\end{array}$ & $\checkmark$ & $v$ & $\checkmark$ & $\checkmark$ & $v$ & $v$ & $\checkmark$ \\
\hline
\end{tabular}

\begin{tabular}{|c|c|c|c|c|c|c|c|}
\hline Padrão & G2 & G3 & G4 & G5 & G6 & G 7 & G8 \\
\hline E1 TEXT DESIGN & $\boldsymbol{v}$ & $v$ & $\boldsymbol{v}$ & 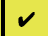 & 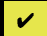 & $\boldsymbol{v}$ & v \\
\hline E2 CONTENT BOX & $\boldsymbol{v}$ & $v$ & $\boldsymbol{v}$ & $\boldsymbol{v}$ & $\boldsymbol{v}$ & $\boldsymbol{v}$ & $\boldsymbol{v}$ \\
\hline E3 PAGING & & & $v$ & & & & \\
\hline E4 SCROLLING & & $\boldsymbol{v}$ & & $\boldsymbol{v}$ & $x$ & $\boldsymbol{v}$ & $x$ \\
\hline $\begin{array}{l}\text { E5 SWITCHING BETWEEN } \\
\text { CONIENT ITEMS } \\
\end{array}$ & $\boldsymbol{v}$ & $\boldsymbol{v}$ & $\boldsymbol{v}$ & $\boldsymbol{v}$ & $\boldsymbol{v}$ & $\boldsymbol{v}$ & a \\
\hline $\begin{array}{l}\text { E6 SYNCHRONISED } \\
\text { CONTENT }\end{array}$ & & $\checkmark$ & $v$ & $v$ & & $v$ & \\
\hline $\begin{array}{l}\text { F2 VOTING AND MULTIPLE- } \\
\text { CHOICE QUESTION }\end{array}$ & & & & $\boldsymbol{v}$ & & & $x$ \\
\hline F3 ALLOCATION OF ITEMS & & & & & & & \\
\hline F4 TEXT COMPLETION & & & & & & & \\
\hline $\begin{array}{l}\text { F5 APPROVAL FOR } \\
\text { CONNECTIVITY }\end{array}$ & ? & \begin{tabular}{|l|l} 
\\
\end{tabular} & ? & ? & ? & ? & ? \\
\hline $\begin{array}{l}\text { G2 ON-SCREEN QWERTY } \\
\text { OR ALPHABBTICAL } \\
\text { KEYBOARD } \\
\end{array}$ & & $x$ & $\boldsymbol{v}$ & $\boldsymbol{v}$ & ? & & \\
\hline $\begin{array}{l}\text { G3 MOBILE PHONE } \\
\text { KEYBOARD }\end{array}$ & & & & & ? & $\boldsymbol{v}$ & \\
\hline $\begin{array}{l}\text { HI ON-SCREIEN } \\
\text { INSTRUCTION }\end{array}$ & $\checkmark$ & & $\checkmark$ & $\checkmark$ & $v$ & $\boldsymbol{v}$ & a \\
\hline H2 HELP SECTION & $v$ & $v$ & $v$ & $v$ & $v$ & $v$ & $v$ \\
\hline I1 ACCESSIBILITYY & $?$ & $?$ & $v$ & $?$ & $?$ & $?$ & $?$ \\
\hline I2 PEIRSONALISATION & $v$ & & $v$ & $v$ & & $v$ & \\
\hline JI CHILDRREN & $x$ & & & & & & \\
\hline
\end{tabular}

According to Table 2, the majority of patterns were used as proposed by Kunert [11]. This is an indication that participants paid attention and recognized the patterns as a reference for their projects. The participants had no previous experience in the use of patterns, so this is a positive indication of the patterns' ease of learning and their use in a practical context.

It was also possible to identify problems with the use of some patterns. G2, for example, used colorful ("C4 Colour Keys") and numerical ("C5 Number Keys") keys to design a game for children. However, these patterns are not compatible with the pattern "J1 Children", created especially for this audience. The "E4 Scrolling" (Scrollbar) was used improperly by groups G6 and G8. G6 did not indicate how to interact properly with the scrollbar and, as G8, did not show the correct status, or percentage, of the scrollbar along the body of the document. Just like G5, G7 and G8 also used more than one layout type in their applications, which may disperse the user's attention. Moreover, G8 did not use the pattern for multiple choices correctly ("F2 Voting and Multiple-Choice Question"), replacing the Arrows and OK ("C2 Arrow Keys" and "C3 OK-Key") keys by the numeric ("C5 Number Keys") keys to select few alternatives in a question. Once the number of choices was not greater than four, the use of arrows and OK keys would require less visual and cognitive effort.

In addition to the mentioned examples, some patterns could only be perceived when analyzing the interactive prototype (e.g., "D6 Going One Level Up" and "E5 
Switching Between Content Items") because they represent dynamic transactions among the prototype's screens. The $\mathrm{CogTool}^{\circledR}$ proved to be effective in identifying these patterns, because it allows the modeling of tasks and the generation of interactive prototypes. Specific patterns for iDTV context, such as "D1 Initial Call to Action" and "D2 Starting", were not considered by most groups, which may indicate lack of contact with iDTV applications. The "D4 Exiting" pattern, which is essential for the user to return to the main television content, was neglected by G2 and G6. This may be a consequence of the inexperience of designers and the lack of contact with television applications.

An important pattern for the Brazilian economic context, "F5 Approval for Connectivity", was neglected in all the projects. Usually, there is a cost associated with connection and data transmission, so ignoring this aspect can trigger problems related to the user experience and also to legal and economic issues. Another important pattern that was neglected was "I1 Accessibility". This pattern was considered by G4, but was overlooked by the other groups preventing people with disabilities to use the application.

\subsection{Preliminary Evaluation}

The responses to the evaluation questionnaire indicated that the design patterns were actually useful in assisting the groups in designing their prototypes. For example, G2 mentioned that "iDTV is still an equipment that few people have access to. The patterns approximate of iDTV most of the participants".

Regarding the use of patterns, groups were asked about the usefulness and contribution of patterns to support the design of application prototypes. Two groups answered that the patterns contributed strongly and were fundamental to project development; four groups answered that they contributed moderately, and in one group, there was disagreement among the participants and the response of the group was classified as indifferent. No group answered that the patterns did not contribute or made the activity difficult.

The groups were also asked to express why and how the patterns were (or were not) important for designing the prototypes. Of the seven groups, only the participant of G7 who reported no contribution of patterns in the previous question did not provide a positive response. For G2, "the patterns were important, because it is hard to think of a project without knowledge about the technology". In this same sense, G6 added that "patterns contributed by providing ideas on how to design the prototype", and G3 mentioned that "the patterns served as inspiration" and "they were not restrictive, because it was possible to identify different ways of presenting the application's content". Similarly to G3, G5 mentioned that "the iDTV patterns supported design choices, but creativity and planning are also important". G4 said that "patterns served to maintain the cohesion of the designed content". Finally, G8 emphasized that "patterns were crucial for explaining the features and limitations that the group would face during the design".

The lack of concern regarding accessibility in the prototypes is critical. Considering the television in a context of high diversity, which is the case in Brazil, ignoring 
accessibility issues means imposing barriers on inclusion and directly impacting values that are of emotional and affective nature (e.g., autonomy, well-being, satisfaction), as well as on the right of access to knowledge and the exercise of citizenship.

Asked about the possibility of an authoring tool specifically for iDTV, two groups answered that an authoring tool would contribute strongly, and five groups said it would contribute moderately. None of the groups said they would be indifferent, did not contribute or made the activity difficult.

Finally, the groups were asked to leave suggestions and ideas for an authoring tool for iDTV applications. G2 and G6 suggested a graphical tool that incorporates predefined patterns for iDTV, similar to Balsamiq ${ }^{\circledR}$. In this tool it would be possible to easily distribute and exchange elements of graphics (e.g., layout, menus, buttons, etc.). Additionally, G7 and G8 envisioned a tool similar to CogTools ${ }^{\circledR}$, which could make the transition between different application screens in a storyboard style, but which would also allow the design of individual layouts. For G3 and G4, it would be interesting to have a tool with an easy-to-use graphical module (beginner mode), but that also generates code and is usable in programming mode.

\section{Conclusion}

Both the use and creation of iDTV applications are still a distant reality for many people as well as for designers involved with the creation of interactive systems. Unlike a PC or Web application, an iDTV design requires some special care due to the lack of specific tools and references for creating applications.

In the case study presented in this paper, the participants, with no previous contact with iDTV applications, used a pattern collection, prototyping tools and techniques inspired on participatory design to support the prototyping of iDTV applications. The results showed that the patterns were widely accepted by the participants and helped to establish a first contact with iDTV design. The misuse of some patterns may indicate the lack of contact with the technology and may also suggest that the patterns must not be taken in isolation. The results obtained from the case study also indicated that the use of an adapted version of the Brain Drawing, combined with the design patterns, was adequate in guiding the designers in the first stages of developing their prototypes. The technique contributed by encouraging participants to outline their views on the project, while the patterns helped to guide their ideas.

Finally, the lack of techniques and specific resources for iDTV makes it difficult to create prototypes or applications. Incorporating design patterns in authoring tools is potentially an important subject for further work.

Acknowledgment. The authors thank the participants of the case study who voluntarily collaborated and authorized the use of their project documentations in this paper. This research is partially funded by $\mathrm{CNPq}$ through the EcoWeb Project (\#560044/2010-0). 


\section{References}

1. Alexander, C.: The Timeless Way of Building. Oxford University Press, Oxford (1979)

2. Baranauskas, M.C.C., Souza, C.S.: Desafio 4: Acesso Participativo e Universal do Cidadão Brasileiro ao Conhecimento. Computação Brasil VII(23), 7 (2006)

3. Borchers, J.: A Pattern Approach to Interaction Design. John Wiley \& Sons Ltd, England (2001)

4. Brazilian Forum for Digital Television, http: / / www . forumsbtvd. org . br

5. Brazilian Presidential Decree No 4.901, http: / / www.planalto.gov.br/ccivil_03/decreto/2003/d4901.htm

6. Cesar, P., Chorianopoulos, K., Jensen, J.F.: Social Television and User Interaction. Computers in Entertainment 6(1), 1-10 (2008)

7. Chung, E.S., Hong, J.I., Lin, J., Prabaker, M.K., Landay, J.A., Liu, A.L.: Development and evaluation of emerging design patterns for ubiquitous computing. In: 5th Conference on Designing Interactive Systems: Processes, Practices, Methods, and Techniques, pp. 233-242. ACM Press, New York (2004)

8. Gamma, E., Helm, R., Johnson, R., Vlissides, J.: Design Patterns: Elements of Reusable Object-Oriented Software. Addison-Wesley, Boston (1995)

9. Ginga-NCL, http: / /www. gingancl.org.br

10. IBGE (National Survey by Household Sample), http: / / www.ibge.gov.br/home/download/estatistica.shtm

11. Kunert, T.: User-Centered Interaction Design Patterns for Interactive Digital Television Applications. Springer, New York (2009)

12. Liu, K.: Semiotics in Information Systems Engineering. Cambridge University Press, Cambridge (2000)

13. Montero, F., Lozano, M., González, P.: A First Approach to Design Web Sites by Using Patterns. In: Second Latin American Conference on Pattern Languages of Programming, pp. 137-158. Microsoft Business Solution, Denmark (2002)

14. Muller, M.J., Haslwanter, J.H., Dayton, T.: Participatory Practices in the Software Lifecycle. In: Helander, M.G., Landauer, T.K., Prabhu, P.V. (eds.) Handbook of HumanComputer Interaction, 2nd edn., pp. 255-297. Elsevier, Amsterdam (1997)

15. Open Ginga, http: / / gingacdn. lavid.ufpb.br/projects / openginga

16. Pereira, R., Buchdid, S.B., Baranauskas, M.C.C.: Keeping Values in Mind: Artifacts for a Value-Oriented and Culturally Informed Design. In: 14th International Conference on Enterprise Information System, pp. 25-34. SciTePress, Portugal (2012)

17. Pereira, R., Buchdid, S.B., Miranda, L.C., Baranauskas, M.C.C.: Considering Values and Cultural Aspects in the Evaluation of Interactive Systems Prototypes. In: International Conference on Information Society, pp. 395-400. IEEE Press, New York (2012)

18. Piccolo, L.S.G., Baranauskas, M.C.C.: Desafios de design para a TV digital interativa. In: VII Brazilian symposium on Human factors in computing systems, pp. 1-10. ACM Press, New York (2006)

19. Sousa, K., Mendonça, H., Furtado, E.: Applying a multi-criteria approach for the selection of usability patterns in the development of DTV applications. In: VII Brazilian symposium on Human factors in computing systems, pp. 91-100. ACM Press, New York (2006)

20. Waisman, T.: Usabilidade em Serviços Educacionais em Ambiente de TV Digital. Doctoral thesis, 201 p. School of Communication and Arts, University of São Paulo (2006) 